\title{
Results and insight gained from applying the EnergyCat energy-saving serious game in UK social housing
}

\author{
Rebecca J. Hafner ${ }^{1}$, Alba Fuertes ${ }^{2}$, Sabine Pahl ${ }^{3}$, Christine Boomsma ${ }^{4}$, Rory V. \\ Jones $^{2}$, Miquel Casals ${ }^{5}$ and Marta Gangolells ${ }^{5}$ \\ ${ }^{1}$ Department of Psychology, University of Bath, Bath, United Kingdom, BA2 7AY \\ *Corresponding author. Email: rjh56@bath.ac.uk; Tel. +44(0) 1225383509 \\ ${ }^{2}$ Department of Architecture and Built Environment, University of Plymouth, Plymouth, \\ United Kingdom, PL4 8AA \\ ${ }^{3}$ School of Psychology, University of Plymouth, Plymouth, United Kingdom, PL4 8AA \\ ${ }^{4}$ Social and Organisational Psychology Department, Leiden University, P.O. Box 9555, \\ 2300RB, Leiden, The Netherlands \\ ${ }^{5}$ Universitat Politècnica de Catalunya, Department of Project and Construction \\ Engineering, Group of Construction Research and Innovation (GRIC), C/ Colom, 11, \\ Ed. TR5, Terrassa, Barcelona 08222, Spain
}

\section{Abstract}

Concerns about climate change associated with the combustion of fossil fuels urge a call for widespread reductions in household energy use. Determining means of achieving this is a key challenge faced by environmental scientists. The current research presents insights gained from a 12-month empirical trial of new serious game for energy, 'EnergyCat'; which was designed to encourage household energy reductions in the UK social housing sector. Effects of gameplay on consumption behaviours and energy awareness were explored using 82 UK social housing households (versus a no-game control). Results indicated the intervention did not lead to any substantive changes in awareness or consumption practices. However, post-intervention feedback highlighted several issues in terms of game design and usability that may explain why the game failed to change behaviour in this instance. We provide a framework of suggestions as to how the game design process could be improved in order to engage residents in future, including use of adaptive fonts for older residents, and provision of clearer instructions on gameplay objectives at the outset. In addition, researchers should ensure close collaboration is maintained with residents throughout the design process in future efforts, in order to maximise likelihood of ongoing engagement from this population.

Keywords: Serious gaming, behaviour change, energy saving, social housing, sustainability 


\section{Introduction}

Reducing energy demand is a core aim of current EU policy, which sets to achieve an $80 \%$ reduction in greenhouse gas emissions by 2050 (in comparison to 1990 levels), in order to keep global warming below $2^{\circ} \mathrm{C}[1,2]$. Yet, this may pose conflicts with important health and social equality agendas. Digital technology provides exciting opportunities for communicating about energy with householders, but may not be suitable for all target audiences. Research has highlighted the effectiveness of 'serious games' in motivating positive behaviour change across a variety of contexts including energy conservation $[3,4,5,6,7]$. However to date, no research (as far as we are aware) has made an attempt to explore whether these findings generalise to vulnerable population subsets, including social housing. The current research was designed to address this lacuna. Specifically, we present insights from the EU Horizon2020 funded multi-disciplinary EnerGAware project (Energy Game for Awareness of energy efficiency in social housing communities); a 12-month longitudinal pilot study into the role of gamification of energy consumption practices as a means of increasing energy awareness and energy conservation within the social housing sector. What follows now is an introduction to the topics of energy behaviour change, serious gaming, and energy use in the social housing sector, followed by a detailed rationale for the current research.

\subsection{Energy behaviour change: Challenges and existing approaches}

Concerns about climate change associated with the combustion of fossil fuels urge a call for a widespread reduction in energy use in homes. Reflecting objectives set out in the European Commission's 2050 low-carbon economy roadmap, current UK government policy expects carbon dioxide $\left(\mathrm{CO}_{2}\right)$ emissions from homes to fall by around $20 \%$ between 2016 and 2030, with options developed to allow near-zero emissions by 2050 [1]. However, whilst consumption in the transport, industry and services sectors have declined in recent years, energy consumption in the domestic sector continues to rise, with a $2.1 \%$ increase per household found between 2015-2016 [8]. Shifting lifestyle choices and perceptions of comfort are contributing to this increase. What is considered a reasonable level of warmth has increased in recent years, resulting in additional energy demand [8]. Determining means of conserving energy in the domestic environment has subsequently been at the forefront of research in recent years. One key avenue of research has explored means of targeting 'curtailment' behaviours. These refer to actions which achieve a reduction in energy consumption because the consumer directly consumes less [9], such as decreasing the length of showers, or switching lights off when one leaves the room. Most curtailment behaviours are daily behaviours which are practiced frequently, and which are, to a large extent, habitual, in the sense that they are typically performed in absence of conscious deliberation. This can be problematic because habitual behaviours are highly resistant to change $[10,11]$.

Another challenge for researchers working in this field stems from the fact that energy is invisible, and is a largely abstract, often intangible concept [12]. This can heighten the challenge associated with engaging consumers in new energy-saving practices, as consumers may find it difficult to link these values to daily energy-using activities [13]. What is more, the temporal distance between engagement in energy consumptive practices and associated costs (such as future energy bills) may also mean consumers experience decreased motivation to act to change their behaviour in the shorter term [11, 14]. This is because consumers typically place less value on future outcomes than nearer term ones, and the rate at which they discount the future is extremely high - well out of line with normative factors such as risk, prevailing interest rates, and inflation [15]. Consequently, given that most people pay for energy long after using it, less weight may be placed on projected future savings when trading off against expected increased short-term costs (in 
terms of increased effort or perceived reductions in hedonic values, such as comfort and enjoyment).

An abundance of initiatives have been developed in order to tackle the problems of energy invisibility and temporal discounting of benefits in order to motivate positive behaviour change for habitual curtailment behaviours. For instance, smart energy monitoring (SEM) systems which provide real-time feedback have been shown to lead to reduced energy consumption $[16,17,18,19,20]$. The theoretical underpinnings of traditional SEM development stem largely from the 'information-deficit model' of behaviour developed by Wilhite and Ling [21]. This asserts that providing real-time feedback of consumption levels helps to fill the 'information vacuum' by increasing knowledge and awareness of the issue [21]; thus increasing the users' ability to gain a mental representation of "diminishing stock" of this otherwise invisible resource. Yet, debate remains as to the interest that users maintain in SEM's over time. Some evidence suggests that use dissipates over time [22], whilst other evidence suggests that effects persist over the medium term [23].

Other strategies have explored the potential of more direct visualisation techniques to reduce energy demand, by using intuitive, tailored images demonstrating where energy is being lost. For instance, showing occupants thermal images, which allowed them to 'see' where their home was losing heat, reduced energy use according to household bills at a 1-year follow-up [24]. Similarly, Boomsma, Goodhew, Goodhew and Pahl [25] found that a thermal image intervention also led to greater vividness when recalling the communication, in comparison to text-only information. It is suggested these vivid representations are effective as they can be internalised in the form of mental images, which evoke emotion and trigger mental goals, thus increasing the availability of information required to enable effective behaviour change [26]. However, these techniques are designed to address thermal energy consumption, and there are challenges to scaling up such tailored techniques to a large population. Consequently, there remains a need for development of an easy-to-scale educational tool that may facilitate greater understanding of energy use surrounding all aspects of household curtailment behaviours. Given the growing evidence that some people respond better to 'playful' forms of information and feedback [27], and that 'learning through doing' is an effective strategy for information assimilation [28], 'gamification' or the development of serious games to educate about energy practices is one potential avenue that may provide an answer to this call.

\subsection{Serious games for energy reduction}

Historically, 'serious games' were defined as 'games with a purpose, which move beyond entertainment to deliver engaging interactive media to support learning in its broadest sense' [29]. Digitalized gamification solutions have since been used to motivate positive behaviour change by including game-like principles within real-world contexts, in order to engage users in 'serious' topics. Indeed, gamers are known to voluntarily invest hours in developing problem-solving skills and achieving mastery [30]. Thus, by presenting a stimulating and engaging interactive environment, it is suggested that serious games offer a unique learning platform that can enable users to develop cognitively, emotionally, and socially, allowing them to maximise their individual potential, and ultimately energizing society to solve humankind's collective challenges [4].

Most serious games use a variation of the 'four-square' framework. This has been defined as the blueprint of the gamification movement, and enables game designers to optimize the potential for behaviour change by tapping in to the principles of motivational techniques already widely established within psychological research [4, 7, 31]. These include, drawing attention to the issue, in order to 'plant the seed' and begin to unfreeze habits [32]; social comparison (e.g. through leader boards), in order to allow for establishment of new social norms [33]; feedback on performance [34]; 'badges' for unlocking achievements as elements of positive reinforcement [35]; goal-setting, which utilises our desire to project a positive and consistent self-image [36, 37]; and rewards and incentives for continued engagement and 
progression [38]. By combining these elements of motivational theory within a 'playful' platform that both engages and enables the user to autonomously seek information, serious games have been shown to have substantial potential for enabling the formation of new sustainable behaviour patterns. Indeed, developments in the field of serious gaming have gained substantial momentum in recent years, and examples of serious gaming being effectively implemented in order to motivate behaviour change now abound across a wide variety of contexts, including health and well-being, education, and sustainability [3, 4, 7]. Within the environmental domain, Ro, Brauer, Kuntz, Shukla and Bensch [39] compared the effectiveness of the "Cool Choices" game in motivating pro-environmental behaviour change across a variety of contexts, including electric usage, transportation, and food choices. In the game, users competed to gain points for completing environmentally sustainable actions. Using two large-scale field trials, results indicated that engagement led to increased reports of householder efforts to save energy and perceived importance of sustainability.

However, examples of serious games specifically focused on reducing energy demand are at an early stage of development. In one example, Reeves, Cummings, Scarborough and Yeykelis [40] explored the potential for the game "Powerhouse" to reduce household electricity consumption. The game used the virtual world of a typical family home to teach users about energy savings, incorporating real time feedback data on consumption levels from utility companies which was presented to users on their personalised 'dashboard', and was found to lead to significant reductions in consumption levels over a 30 day trial period. Other examples include the games "Green My Place" [41], and "Energy Chickens" [42], both of which were effective in leading to short term reductions in energy demand, with savings typically ranging between $2-30 \%$ (for a review please see [43, 44, 45]).

As such, there certainly appears to be potential for serious gaming to change behaviour within the context of energy reduction. However, there remains a need to explore the longevity of these effects, given most existing examples within the field provide illustration of behaviour change over relatively short time periods (see, [44]). In addition, the question remains as to whether the effects generalise to vulnerable populations, such as social housing. The current research was designed to address this lacuna. Specifically, we present a longitudinal pilot exploration of the efficacy of the serious game 'EnergyCat' as a behaviour change tool in energy demand reduction in this context. The game targeted more efficient energy practices at home, with a view to encouraging energy conservation. The study followed a sample of social housing tenants over a 12-month period, allowing for a thorough exploration of the process of implementing the game, and any effects of the game on behaviour over time. A detailed rationale is provided in Section 1.5, following an introduction to our target population: the social housing sector in the UK (Section 1.3), as well as a description of the EnergyCat game (Section 1.4).

\subsection{The social housing sector in the UK}

Housing is the single highest expenditure item for Europeans, at about a quarter of the average total household budget for all housing in 2015, increasing from $21.7 \%$ in 2000 [46]. What is more, research has shown that there is a direct correlation between housing and rising inequality at a global scale, with a substantial increase in the share of poor households pushed into poverty due to rising housing costs across many European countries in recent years [46]. Social housing provides low-income households with subsidised, sub-market rents, and provides a crucial role for nearly four million households within the UK [47]. However, given rising financial pressures within the housing market, social housing residents are now substantially more concentrated within the poorer parts of income distribution than in the past. Research has shown that $70 \%$ of current social housing residents have incomes within the lowest two-fifths of overall income distribution within the UK, compared with only 19\% in the top half in 2004-2005 [47]. What is more, the proportion of social householders in paid employment fell from 
47 to 32 per cent between 1981 and 2006; resulting in twice the national rate of unemployment for those of working age for this population subset. Residents also have high rates of disability, are more likely than other tenures to be lone parents or single, and to be aged over 60 [47]. One result of this is that the experience of fuel poverty for this population is widespread. Indeed, the percentage of the population declaring they are unable to keep their home adequately warm increased from $5.7 \%$ in 2005 to $10.6 \%$ in 2013 according to EU SILC [46]. This is driven by rising fuel prices that are not offset by efficiency improvements, which are often lacking in poorer households. In addition, lowincome earners are likely to pay more per unit for energy as they are often not in a position to choose payment plans that offer reduced tariffs, such as direct debit [48]. We theorised that serious games for energy reduction may provide a novel way to achieve energy reductions in the social housing sector, given demonstrable impacts on consumption levels found across wider populations (see [39-42]).

\subsection{The 'EnergyCat' game}

Finjheer and van Oostendorp [49] provide a review of steps that should be taken in order to effectively design a household energy saving game. The 'EnergyCat' game was designed with this research in mind, and was co-developed to meet the specific needs and interests of the social housing sector. Specifically, in line with suggestions made by Finjheer and van Oostendorp [49], a range of measures were taken to ensure user views were taken on board to develop the game, prior to commencing the pilot trial. First, we consulted with the housing company on the technical energy efficiency opportunities available to the housing residents (which then informed the options in the game), and on the research process (e.g., how would it fit into residents' practices and commitments). We also ran two survey studies before the development to understand our target population and select a smaller group of participants for the pilot study, the first one on the entire resident population and the second one on those who had been selected. This process and outcomes are documented in Boomsma et al., [43]. The games developer, FremenCorp, then ran a series of resident workshops and focus groups that focused on overall theme and focus for the game, characters, visuals etc. These interactions highlighted that residents wanted a fun and enjoyable game that was easy to follow, and that provided interesting challenges and tips surrounding domestic energy use. The sessions also revealed that the residents preferred a game with visuals quite close to their own experience, their homes and home city, rather than more abstract or futuristic representations, so this was implemented.

In the game, the resident cat protagonist (nicknamed 'EnergyCat') aimed to teach its human residents about the most effective ways to use energy, through the provision of ingame tips and information. A cat was chosen as a slightly removed, quirky, independentminded character who could observe and comment on human action without being seen as threatening, and which would allow us to meet our user-objective of a fun and enjoyable game format. Users, via the cat, had the goal of achieving efficiency whilst also maintaining the thermal comfort of the human residents. The game was composed of two systems (or "modes"), which interacted to promote a unique game experience, the first of which was a 'house customisation' mode. This was loosely based on "the sims" life simulation video game, and allowed users to create their dream home using in-game currency gained as a result of achieving energy savings. This decision regarding reward structure was based on the developers' past experience, and upon suggestions made by Finjheer and van Oostendoorp [49] regarding personalisation as a key mechanism to encourage engagement with serious games for energy. However, we note that with a different reward structure results could look different, and this remains an interesting avenue for future research. The second game mode was the "mission mode"; which was designed to provide information and narrative surrounding energy efficiency practices and behaviours in the domestic environment. In order to achieve this a variety of in-game hints and tips were provided, which were tailored to 
different areas of potentially high wastage around the home. In addition, users could advance to different 'levels' once optimal energy use in their own home was achieved, by helping neighbours with specific problems and requirements to achieve energy reductions. Full details of the game development process are provided in EnerGAware project deliverable reports [50-51]. Figure 1 provides a sample screenshot of the game platform.

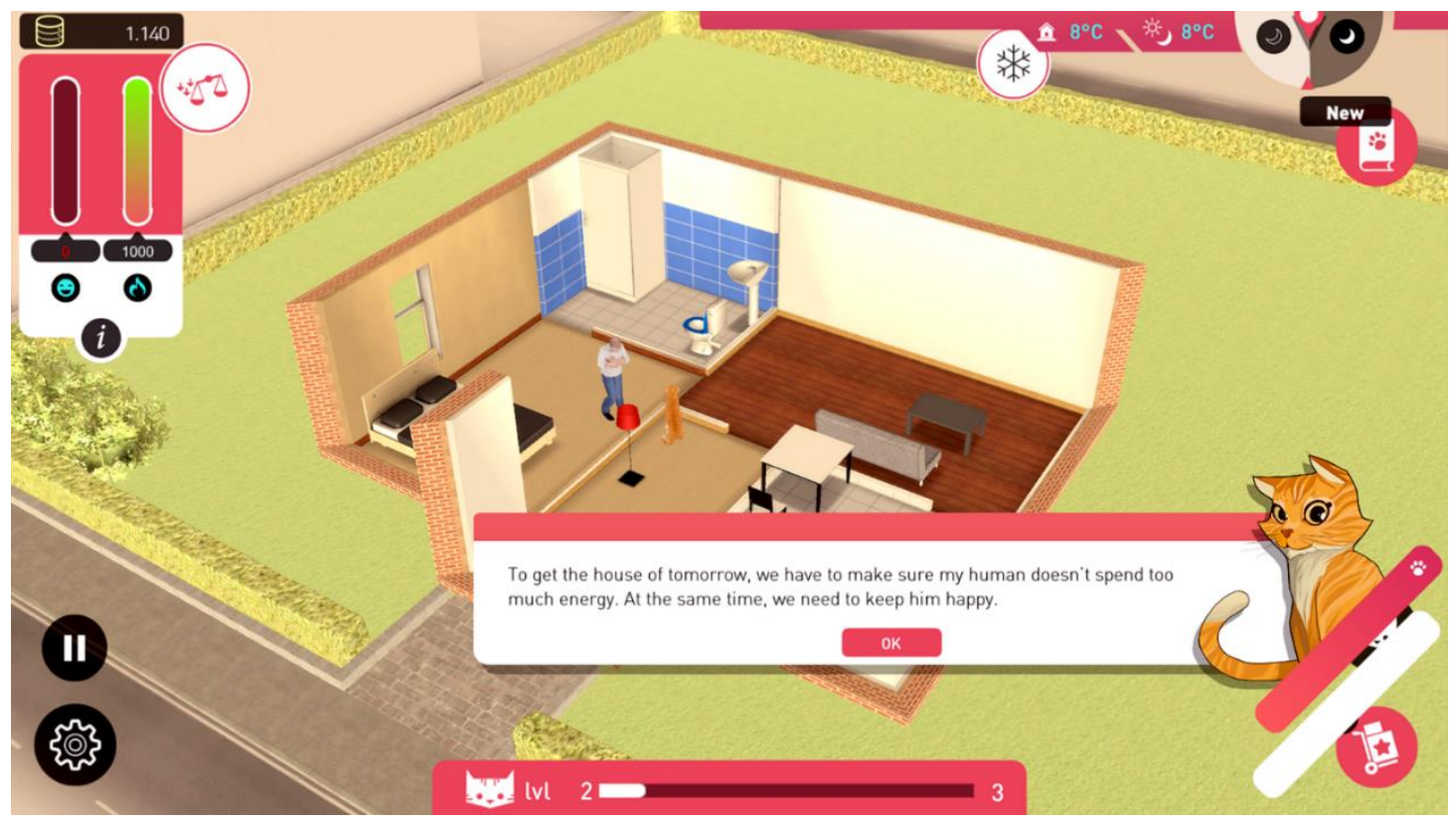

Figure 1. Sample screenshot of EnergyCat game platform.

Previous research has shown that the behaviour of building occupants can influence about $40 \%$ of the buildings' energy use [52]. Within the social housing sector, previous interventions which have sought to teach occupants how to use energy more efficiently (for example by turning the heating down rather than opening windows), have achieved energy savings of between $7-25 \%[53,54,55]$. Consequently, on this basis, and taking into account the range of savings achieved following previous serious game interventions focused on wider populations [40-42], it was estimated that the EnergyCat serious game could achieve savings of between $15-30 \%$, or up to $127.95 \mathrm{Mtoe} / \mathrm{yr}$ in the UK.

\subsection{Rationale and approach}

The current research aimed to explore whether previous successes of serious games for energy reduction would extend to the social housing sector, as well as exploring the longevity of behaviour change effects of serious gaming in triggering lasting behaviour change in this context. Social housing residents were divided into a gaming group ('experimental condition') and a no-gaming group ('control condition'). In a 12-month empirical trial householders' energy awareness and engagement in efficiency behaviours were explored, versus the no-game control.

H1: Using the EnergyCat serious game will lead to increased energy awareness. We expect that at the final term stage, subjects in the experimental condition will report increased energy awareness in contrast to: a) the control group, and b) baseline measures.

H2: Using the EnergyCat serious game will lead to increased engagement in energysaving behaviours. We expect that at the final term stage, subjects in the experimental 
condition will report increased engagement in energy-saving behaviours in contrast to: a) the control group, and b) baseline measures.

\section{Methodology}

\subsection{Participants}

Eighty-two social housing households (primary respondent gender: 45\% male, $49 \%$ female, $6 \%$ missing) were selected to participate in the pilot trial from a large pool of all 2772 social houses managed by project partner DCH in Plymouth, UK. The pool was representative of typical demographics found in the social housing sector [56]; the mean age for the primary respondent was 54 , with most subjects $(63.6 \%)$ stating they were aged 50 years or older, and either retired $(36 \%)$ or in employment $(37 \%)$. There was an even split in the percentage of subjects in receipt of welfare benefits (45\% yes, $45 \%$ no, $10 \%$ missing), and the majority stated that either they (39\%) or another member of the household (27\%) had a disability.

\subsection{Procedure and materials}

The 82 pilot homes were allocated to either the experimental $(N=42)$ or control $(N=40)$ condition using a pairing approach, in which two near-identical houses were identified on the basis of socio-demographic and dwelling characteristics, and one randomly assigned to each group. This was done in order to ensure the groups were as similar as possible at the start of the intervention, thus ensuring a valid baseline point for comparison. Households were visited at the start of the intervention (January 2017), and were given a free Samsung tablet as an incentive for taking part. For the experimental subjects, the tablet had a pre-installed version of the game 'EnergyCat', which they were invited to play for the duration of the trial period, for as long and as frequently as they liked. Conversely, subjects in the control condition were simply given the tablet, without the game. This was done in the interests of methodological consistency, given that a tablet could be perceived as a valuable gift and might otherwise have made one group more willing to engage. At this stage, subjects were asked to complete a baseline survey, designed to assess prior energy awareness and understanding, and self-reported engagement in energy saving behaviours. At the end of the trial period (December 2017) the pilot homes were sent a final term survey, which replicated the baseline in order to determine the overall impact of the intervention in motivating behaviour change during the trial period. $£ 20$ shopping vouchers were given as an incentive for completion of each survey. In total, 78 of the households completed the baseline survey, and 60 households completed the final term survey (respective response rates $88.6 \%$ and $68.18 \%$ ), giving a total of 60 households that completed both surveys.

\subsection{The surveys and dependent variables (DV's)}

The surveys included questions designed to assess energy awareness and understanding, and engagement in various energy saving behaviours. In terms of energy awareness and understanding (DV1), nine items were included in order to explore perception and motivations, perceived control, and social norms (items adapted from [57, 58]). Subjects were asked to rate the extent to which they agreed with statements such as: 'I don't understand how my home uses energy'. Responses were given on a 5-point Likert-scale ranging from 1 (Strongly disagree) to 5 (Strongly agree) (all items for this measure are presented in Table 1). A mean score for energy awareness was calculated $(\alpha=.61)$. In terms of self-reported engagement in energy saving behaviours (DV2), subjects were asked to rate how frequently they had engaged in 23 specific energy saving behaviours over the last 3 months, such as: ' $I$ 
try to minimise my shower time to 5 minutes' (items adapted from 16, 59, 60). Responses were given on a 5-point Likert-scale ranging from 1 (Never) to 5 (Always) (items presented in Table 2). A mean score for self-reported energy saving behaviours was computed $(\alpha=.96)$, indicating high internal consistency.

In addition to the main DV's, the final term survey also included eleven items on psychological barriers to behaviour change (DV3) in order to determine which factors, if any, may help to explain any impact of the game on participants' energy-related behaviours. The items were based upon previous literature which has identified prominent barriers to behaviour change in the context of energy reduction ([11,61-62]). Subjects were asked to rate the extent to which each of 11 potential reasons prevented them from using less energy at home. These included: 'health reasons', 'no interest', and 'hard to change my behaviour' (items presented in Table 3). Responses were given on a 5-point Likert-scale ranging from 1 (Strongly disagree) to 5 (Strongly agree).

The final term survey also included several items designed to assess interest/motivation to play the EnergyCat game (DV4), which were only given to subjects in the experimental group. Subjects were asked: 'Have you played the game EnergyCat?' and 'How many times have you played the EnergyCat game so far?' Subjects were also asked to complete the SUS usability scale, adapted from Brooke [64]. This is a standard scale widely used to measure user experience of digital technology applications. For this, subjects were asked to rate agreement with 11 statements designed to provide an assessment of overall usability, such as: 'The EnergyCat game is easy to use', using a 5-point Likert scale ranging from 1 (Strongly agree) to 5 (Strongly disagree). Finally, in addition to this quantitative measure of usability, the final term survey was also designed to ascertain a measure of qualitative feedback on EnergyCat to further inform future intervention development. Subjects in the experimental condition were asked to describe what they liked/disliked about the game. Or, if they had not played, what would need to be improved in order to encourage them to play.

\subsection{Analytical approach}

The present research design involves a temporal factor and two experimental conditions, so a mixed ANOVA is the most comprehensive way of testing baseline differences and differences in response to the different conditions over time for DVs 1 and 2 [63]. This tested our overall hypotheses that the game would change residents' awareness and behaviour whereas no such change should be found in the control condition. In addition, we then used the same analytical approach to undertake exploratory analysis at the item level. For DV3 we change the analytic approach because the key question here was what the main barriers were for residents in general. To test this, we first ran an overall one-way ANOVA to see if barriers were rated differently. We then undertook post-hoc pairwise comparisons to pinpoint which barriers were statistically different from each other. Finally, DV4 (overall perceptions and the SUS) were only reported at the descriptive level; no statistical analysis was undertaken here.

\section{Results}

\subsection{Energy awareness (DVI)}

A 2 (condition: experimental vs. control) x 2 (time: baseline vs. final term) mixed analysis of variance (ANOVA) revealed no effect of time on energy awareness: $F(1,55)=.82, p=.37$, $\eta^{2}=.02$, and no interaction between time and condition: $F(1,55)=.73, p=.40, \eta^{2}=.01$. Similar average levels of energy awareness were found in the experimental $(M=3.45)$ vs. control $(M=3.73)$ conditions at the final term stage. In addition, similar levels of energy awareness were found in the experimental group at the baseline $(M=3.61)$ vs. final term stage $(M=3.45)$, suggesting the intervention was not effective in leading to changes in energy awareness either between conditions or over time. 
We then conducted further exploratory analyses using a series of mixed ANOVAs in order to explore any impact of the intervention on individual energy awareness items. Results are displayed in Table 1. Substantiating our previous findings, analyses revealed only two significant effects across the nine energy awareness items. In the first instance, a significant effect of time was found for the item: 'I do not understand how my home uses energy': $F(1,54)=4.45, p=.04, \eta^{2}=.08$ (Table 1). Specifically, subjects were found to be more likely to agree with this statement at the baseline versus final term stage. However, the lack of an interaction between time and condition: $F(1,54)=1.42, p=.24$, $\eta^{2}=.03$ (Table 1) demonstrates that this was not specific to the experimental condition, but rather was part of a larger effect of increased awareness across conditions, simply as a result of taking part in the EnerGAware programme. We return to a discussion of the implications of this finding in section 4 .

In the second instance, a significant interaction was found between time and condition for the item: 'My friends and family say it's important to save energy': $F(1,55)=4.60$, $p=.04, \eta^{2}=.08$ (Table 1). Interestingly, although no main effect of time was found for this item (Table 1), the presence of the interaction shows subjects were found to be more likely to agree with this statement at the final term vs. baseline stage in the experimental condition, and vice versa in the control condition. Paired t-tests were then conducted in order to follow up on this interaction. The t-tests revealed that the effect for the experimental condition over time was not statistically significant: $t(27)=-1.06, p=.30$, Cohen's $d=.23$.

However, the effect for the control condition over time was found to be significant: $t(28)$ $=2.07, p=.05$, Cohen's $d=.33$ (representing a small effect size). Consequently, the interaction predominately reflects the finding that subjects in the control condition were less likely to state that their friends and family said it was important to save energy at the final term vs. baseline stage. One potential explanation for this may involve the lack of direct experimental intervention in this condition, which could have caused the subject and peers to simply lose interest in the topic of energy saving, perhaps somewhat disillusioned with the process given a lack of easily discernible energy-related benefits of engagement over time. However, as no additional in-depth measures of social influence were included in the surveys, at this stage this suggestion remains speculative, and could usefully be followed up in further research. For the time being, however, this effect is of comparatively reduced interest in terms of discerning wider implications of the current research. This is due to: a) the small effect size for this finding, $b$ ) the fact that no other differences were found for the control group over time, and c) our reduced empirical focus on findings which are driven by, or specific to, the control group. Consequently, this effect is not subject to further scrutiny.

\subsection{Self-reported engagement in energy saving behaviours (DV2)}

Replicating the energy awareness analyses, a 2 (condition: experimental vs. control) x 2 (time: baseline vs. final term) mixed ANOVA revealed no effect of time on engagement in the energy saving behaviours: $F(1,55)=2.28, p=.14, \eta^{2}=.04$, and no interaction between time and condition: $F(1,55)=.13, p=.72, \eta^{2}=.002$. Similar average levels of engagement with the energy saving behaviours were found in the experimental $(M=4.09)$ vs. control $(M=4.03)$ conditions at the final term stage, and for the experimental condition at the baseline $(M=4.01)$ vs. final term stage $(M=4.09)$. Paralleling the energy awareness analyses, this appears to suggest that the intervention was not effective in increasing engagement with the energy saving behaviours either between conditions, or over time.

Replicating the energy awareness analyses, additional exploratory analyses were then conducted using a series of 2 (condition: experimental vs. control) x 2 (time: baseline vs. final term) mixed ANOVAs to explore the impact of the intervention on individual energy saving behaviour items. A main effect of time was found for one out of the twenty-three items: 'I make sure that the windows are closed when the heating is on', $F(1,54)=5.03$, $p=.03, \eta^{2}=.09$. However no interaction for time and condition was found for this item: 
pag. 36

$F(1,54)=.06, p=.80, \eta^{2}=.001$, illustrating this was a uniform effect, and was not specific to the experimental manipulation. There were no other significant effects of time (all $F_{\mathrm{s}} \leq$ $3.41 \mathrm{ps} \geq .07$ ), and no significant interactions between time and condition (all $F_{\mathrm{s}}<2.38$ $p s>.10)$ for any of the other twenty-two energy saving behaviours. This provides support for our main analyses, and verifies that the intervention was not effective in encouraging any overall changes in engagement with the energy saving behaviours either over time, or according to condition. In the interests of completeness, descriptive statistics for each item are displayed in Table 2. 
Table 1. Descriptive statistics and within subjects' effects for individual item energy awareness analyses.

\begin{tabular}{|c|c|c|c|c|c|c|c|c|c|c|c|c|}
\hline \multirow{4}{*}{ Item } & \multicolumn{8}{|c|}{ Descriptive statistics } & \multirow{2}{*}{\multicolumn{4}{|c|}{ Tests of within subjects' effects }} \\
\hline & \multicolumn{4}{|c|}{ Baseline stage } & \multicolumn{4}{|c|}{ Final term stage } & & & & \\
\hline & \multicolumn{2}{|c|}{$\begin{array}{l}\text { Experimental } \\
\text { group }\end{array}$} & \multicolumn{2}{|c|}{ Control group } & \multicolumn{2}{|c|}{$\begin{array}{l}\text { Experimental } \\
\text { group }\end{array}$} & \multicolumn{2}{|c|}{ Control group } & \multirow[b]{2}{*}{$\begin{array}{l}\mathrm{F} \\
\text { value }\end{array}$} & \multirow{2}{*}{$\begin{array}{l}\text { Time } \\
\text { Sig. (two- } \\
\text { tailed) }\end{array}$} & \multicolumn{2}{|c|}{ Time*Condition } \\
\hline & Mean & $(\mathrm{SD})$ & Mean & (SD) & Mean & $(\mathrm{SD})$ & Mean & $(\mathrm{SD})$ & & & $\begin{array}{l}\mathrm{F} \\
\text { value }\end{array}$ & $\begin{array}{l}\text { Sig. } \\
\text { (two- } \\
\text { tailed) }\end{array}$ \\
\hline $\begin{array}{l}\text { 'I don't understand how my } \\
\text { home uses energy' }\end{array}$ & 3.18 & $(1.49)$ & 2.61 & $(1.34)$ & 2.54 & $(1.37)$ & 2.43 & $(1.14)$ & 4.45 & $.04 *$ & 1.42 & $.24^{\mathrm{ns}}$ \\
\hline $\begin{array}{l}\text { 'I am worried about my } \\
\text { energy bills' }\end{array}$ & 3.18 & $(1.25)$ & 2.97 & $(1.40)$ & 2.89 & (1.07) & 3.10 & $(1.40)$ & .26 & $.61^{\mathrm{ns}}$ & 2.16 & $.15^{\mathrm{ns}}$ \\
\hline $\begin{array}{l}\text { 'I often think about how I can } \\
\text { save energy" }\end{array}$ & 4.00 & $(.92)$ & 4.00 & $(1.17)$ & 3.93 & $(1.04)$ & 4.03 & $(1.05)$ & .01 & $.91^{\mathrm{ns}}$ & .10 & $.76^{\mathrm{ns}}$ \\
\hline $\begin{array}{l}\text { 'I have control over how } \\
\text { much energy is consumed in } \\
\text { my home' }\end{array}$ & 3.64 & (1.19) & 4.03 & $(1.05)$ & 3.57 & $(1.17)$ & 4.00 & $(.96)$ & .16 & $.70^{\mathrm{ns}}$ & .02 & $.89^{\mathrm{ns}}$ \\
\hline $\begin{array}{l}\text { 'I am not able to save any } \\
\text { more energy" }\end{array}$ & 3.25 & $(1.21)$ & 3.50 & (1.11) & 3.18 & (1.06) & 3.75 & (1.04) & .44 & $.51^{\mathrm{ns}}$ & 1.42 & $.24^{\mathrm{ns}}$ \\
\hline $\begin{array}{l}\text { 'I am prepared to save energy } \\
\text { with the right support' }\end{array}$ & 4.39 & $(.63)$ & 4.17 & $(.89)$ & 4.04 & $(.92)$ & 4.28 & $(.92)$ & 1.03 & $.32^{\mathrm{ns}}$ & 3.38 & $.07 \dagger$ \\
\hline $\begin{array}{l}\text { 'My friends and family say } \\
\text { it's important to save } \\
\text { energy' }\end{array}$ & 3.75 & $(.89)$ & 4.00 & $(1.00)$ & 3.96 & $(.96)$ & 3.66 & $(1.05)$ & .25 & $.62^{\mathrm{ns}}$ & 4.60 & $.04 *$ \\
\hline $\begin{array}{l}\text { 'I don't trust my energy } \\
\text { supplier' }\end{array}$ & 3.00 & $(1.22)$ & 2.83 & $(1.20)$ & 3.07 & $(1.25)$ & 2.79 & $(1.26)$ & .01 & $.92^{\mathrm{ns}}$ & .09 & $.77^{\mathrm{ns}}$ \\
\hline $\begin{array}{l}\text { 'I can easily imagine how } \\
\text { much energy my home uses' }\end{array}$ & 3.46 & (1.04) & 3.66 & $(.94)$ & 3.54 & $(1.00)$ & 3.66 & $(.81)$ & .07 & $.79^{\mathrm{ns}}$ & .07 & $.79^{\mathrm{ns}}$ \\
\hline
\end{tabular}

Note: ${ }^{\mathrm{ns}}=$ not significant, $\dagger=p=.07, *=p<.05$. 
Table 2. Descriptive statistics for individual energy saving behaviours over time according to condition.

\begin{tabular}{|c|c|c|c|c|c|c|c|c|}
\hline \multirow{3}{*}{ Item } & \multicolumn{4}{|c|}{ Baseline stage } & \multicolumn{4}{|c|}{ Final term stage } \\
\hline & \multicolumn{2}{|c|}{$\begin{array}{l}\text { Experimental } \\
\text { group }\end{array}$} & \multicolumn{2}{|c|}{ Control group } & \multicolumn{2}{|c|}{$\begin{array}{l}\text { Experimental } \\
\text { group }\end{array}$} & \multicolumn{2}{|c|}{ Control group } \\
\hline & Mean & (SD) & Mean & (SD) & Mean & $(\mathrm{SD})$ & Mean & (SD) \\
\hline $\begin{array}{l}\text { 'I make sure that the } \\
\text { curtains/blinds are closed } \\
\text { when the heating is on in the } \\
\text { evening' }\end{array}$ & 4.25 & $(1.24)$ & 4.25 & (1.18) & 4.36 & $(1.10)$ & 4.57 & $(.79)$ \\
\hline $\begin{array}{l}\text { 'I make sure that the curtains } \\
\text { are open when the sun is } \\
\text { shining in winter' }\end{array}$ & 4.68 & (.67) & 4.54 & $(.76)$ & 4.54 & $(.84)$ & 4.73 & $(.53)$ \\
\hline $\begin{array}{l}\text { 'I make sure the windows are } \\
\text { closed when the heating is on' }\end{array}$ & 4.79 & $(.57)$ & 4.61 & $(.69)$ & 4.96 & $(.19)$ & 4.75 & $(.52)$ \\
\hline $\begin{array}{l}\text { 'I change the temperature on } \\
\text { my thermostat' }\end{array}$ & 3.70 & $(1.26)$ & 3.56 & $(1.45)$ & 3.70 & $(1.26)$ & 3.88 & $(1.30)$ \\
\hline $\begin{array}{l}\text { 'I adjust the temperature on } \\
\text { my radiators' }\end{array}$ & 3.15 & $(1.59)$ & 2.83 & $(1.61)$ & 3.46 & $(1.58)$ & 3.21 & $(1.47)$ \\
\hline $\begin{array}{l}\text { 'I try to minimise my shower } \\
\text { time to } 5 \text { minutes' }\end{array}$ & 3.50 & $(1.24)$ & 3.30 & $(1.52)$ & 3.54 & (1.14) & 3.43 & (1.38) \\
\hline $\begin{array}{l}\text { 'I make sure that no appliances } \\
\text { are left on standby' }\end{array}$ & 2.86 & $(1.43)$ & 3.27 & $(1.54)$ & 2.79 & $(1.37)$ & 3.65 & (1.29) \\
\hline $\begin{array}{l}\text { 'I make sure that chargers are } \\
\text { unplugged when not in use' }\end{array}$ & 3.11 & $(1.66)$ & 3.82 & $(1.63)$ & 3.32 & $(1.61)$ & 4.14 & $(1.51)$ \\
\hline $\begin{array}{l}\text { 'I shut down my computer } \\
\text { when it is not in use' }\end{array}$ & 4.08 & $(1.50)$ & 3.94 & (1.39) & 4.35 & $(1.38)$ & 4.19 & (1.17) \\
\hline $\begin{array}{l}\text { 'I only boil the water I need in } \\
\text { the kettle' }\end{array}$ & 4.37 & (.88) & 3.97 & $(1.24)$ & 4.33 & (1.14) & 3.90 & $(1.35)$ \\
\hline $\begin{array}{l}\text { 'I make sure that I use the right } \\
\text { sized hob ring when cooking' }\end{array}$ & 4.52 & $(.85)$ & 4.50 & $(.81)$ & 4.63 & (.69) & 4.42 & (.99) \\
\hline $\begin{array}{l}\text { 'I make sure that the fridge and } \\
\text { freezer doors are not open } \\
\text { longer than necessary' }\end{array}$ & 4.75 & $(.70)$ & 4.76 & $(.58)$ & 4.86 & $(.36)$ & 4.90 & $(.31)$ \\
\hline $\begin{array}{l}\text { 'When no one is home the } \\
\text { heating is off' }\end{array}$ & 4.40 & $(1.16)$ & 4.00 & $(1.33)$ & 4.20 & $(1.15)$ & 4.14 & $(1.24)$ \\
\hline $\begin{array}{l}\text { 'When I am the last to leave a } \\
\text { room I turn the lights off' }\end{array}$ & 4.64 & (.68) & 4.52 & $(.87)$ & 4.64 & $(.91)$ & 4.48 & $(.99)$ \\
\hline $\begin{array}{l}\text { 'I wear very warm clothes in } \\
\text { winter so I can keep the } \\
\text { heating on low or off' }\end{array}$ & 3.93 & $(1.09)$ & 3.85 & $(1.13)$ & 3.79 & $(1.37)$ & 3.70 & $(1.20)$ \\
\hline $\begin{array}{l}\text { 'When I buy a new appliance I } \\
\text { look at the energy labels' }\end{array}$ & 3.96 & $(1.09)$ & 3.84 & $(1.31)$ & 4.04 & $(1.29)$ & 3.64 & $(1.47)$ \\
\hline $\begin{array}{l}\text { 'I turn off the heating in rooms } \\
\text { that are not normally used' }\end{array}$ & 4.08 & $(1.35)$ & 3.70 & $(1.74)$ & 3.96 & $(1.40)$ & 3.39 & $(1.73)$ \\
\hline 'I close doors between rooms' & 3.32 & $(1.36)$ & 3.37 & $(1.45)$ & 3.71 & $(1.30)$ & 3.22 & $(1.58)$ \\
\hline $\begin{array}{l}\text { 'I only use my washing } \\
\text { machine when I have a full } \\
\text { load of washing' }\end{array}$ & 4.48 & $(.80)$ & 4.62 & $(.57)$ & 4.60 & $(.57)$ & 4.62 & $(.64)$ \\
\hline $\begin{array}{l}\text { 'When I am the last to leave a } \\
\text { room I turn off the appliances } \\
\text { that are on' }\end{array}$ & 4.00 & $(1.39)$ & 4.29 & $(1.15)$ & 4.07 & $(1.30)$ & 4.46 & $(.84)$ \\
\hline $\begin{array}{l}\text { 'I only use my dishwasher } \\
\text { when it is full' }\end{array}$ & 4.56 & (1.01) & 4.60 & $(.55)$ & 4.67 & $(.71)$ & 4.80 & (.45) \\
\hline $\begin{array}{l}\text { 'I use energy saving modes on } \\
\text { my appliances' }\end{array}$ & 3.94 & $(.94)$ & 3.76 & $(1.20)$ & 4.11 & $(1.02)$ & 4.00 & $(1.22)$ \\
\hline $\begin{array}{l}\text { 'I tell other people to do things } \\
\text { that save energy' }\end{array}$ & 3.35 & $(1.23)$ & 3.04 & $(1.46)$ & 3.42 & $(1.33)$ & 3.15 & (1.64) \\
\hline
\end{tabular}




\subsection{Sub-group analyses}

Slightly less than half (41.4\%) of the subjects in the experimental group reported playing the game, at an average of 17 times, for an average duration of 16.5 minutes. Consequently, in the interests of completeness, we then re-ran the main analyses using only those subjects who had reported playing the game (versus. control), in order to explore whether this may go some way to explaining the lack of any significant differences between conditions in our earlier analyses. Results were found to directly parallel the main analyses. In terms of energy awareness (DV1), a 2 (condition: experimental played vs. control) x 2 (time: baseline vs. final term) mixed ANOVA revealed no effect of time on overall energy awareness: $F(1,36)=1.10$, $p=.30, \eta^{2}=.03$, and no interaction between time and condition: $F(1,36)=1.10, p=.30, \eta^{2}=$ .03. Similarly, in terms of self-reported engagement with the energy saving behaviours (DV2), a 2 (condition: experimental played vs. control) x 2 (time: baseline vs. final term) mixed ANOVA revealed no main effect of time: $F(1,36)=3.12, p=.09, \eta^{2}=.08$, and no interaction between time and condition: $F(1,36)=.97, p=.33, \eta^{2}=.03$. Thus, it appears that the lack of any notable effects on energy awareness or energy saving behaviours in our earlier analyses cannot be attributed to a lack of engagement with the game amongst participants in the experiment group, as even when we focus on subjects who reported playing, the same pattern of results is found. As such it appears that the EnergyCat game, as presented here, was simply not effective in changing energy awareness, or in encouraging residents to engagement with energy saving behaviours. We later return to a discussion of possible explanations for this finding, as well as implications for future research and intervention development (Section 4.0). Given that no notable differences were found whether we focus only on those subjects who reported playing the game, or the whole experimental group, in the interests of statistical power we now return to using the whole data set for the remaining analyses.

\subsection{Psychological barriers to behaviour change (DV3)}

The following analyses were conducted across conditions, in order to provide insight into the main barriers to behaviour change faced by all domestic energy users within the social housing sector. A one-way repeated measures ANOVA revealed the psychological barriers to behaviour change varied in importance: $F(10,250)=4.62, p<.001, \eta^{2}=.16$. Descriptive statistics for the barriers to behaviour change are presented in Table 3. Posthoc pairwise comparisons revealed that agreement with the statement: 'I don't want to feel cold or uncomfortable at home', was significantly higher than all other barriers, suggesting this plays a vital role in explaining why subjects are not able to use less energy. Two other items were found to contrast significantly with several other barriers. These were: 'Health reasons' and 'Already using very little'. In both cases, these reasons were rated as significantly more important than other potential reasons. In contrast, generally low levels of agreement were found for the statement: 'Don't want to / not interested' (Table 3), suggesting lack of interest does not explain reduced efforts to use less energy for this population. Rather, the main barriers to behaviour change were found to centre around low baseline levels of energy usage in this sector, health reasons, and the perception that further reductions would be deterimental to comfort levels when at home. 
Table 3. Descriptive statistics for barriers to behaviour change analyses.

\begin{tabular}{lll}
\hline Item & M & (SD) \\
\hline I don't know how to & 2.69 & 1.41 \\
Health reasons & 3.38 & 1.68 \\
Don't want to / not interested & 2.23 & 1.37 \\
No financial incentive & 2.88 & 1.42 \\
Hard to change my behaviour & 3.00 & 1.41 \\
Don't want to feel cold or uncomfortable at home & 4.08 & .98 \\
No personal control over my household energy use & 2.54 & 1.53 \\
Already using very little & 3.23 & 1.11 \\
No-one else is doing it & 2.81 & 1.55 \\
Other members of my household aren't willing / able to & 2.85 & 1.59 \\
No interest from family / friends / neighbours & 2.50 & 1.58 \\
\hline
\end{tabular}

\subsection{Perceptions of the game and interest/motivation to play (experimental group only) (DV4)}

Subjects who had not played the game were asked to describe the main reason(s) why they had not played. The majority of responses were found to centre around issues of usability, and/or a lack of time or lack of interest in playing games, e.g.:

"It doesn't work and I can't see the tiny font"

"I just do not have time for gaming!"

Subjects who had played the game were asked to complete the SUS usability scale, adapted from Brooke [64]. According to Brooke [64], a score of below 68 on the SUS scale may be regarded as below average in terms of usability. The average SUS score for the EnergyCat game was found to be 40.83 (ranging between 10 and 52.5), demonstrating that the game was generally not perceived to be very user friendly. The responses to the questions that are part of the SUS scale provide further insight into the reported usability of the game. Specifically, analysis revealed high agreement with three statements: 'The EnergyCat game is unnecessarily complicated' $(M=4.00, S D=1.10)$, 'I would need more support to be able to play the EnergyCat game' $(M=4.00, S D=1.10)$, and 'The EnergyCat game is very difficult to use' $(M=4.00, S D=1.10)$.

This suggests that the perceived complexity of the game and lack of support may be key reasons why the game had limited impact in motivating positive behaviour change, and may also explain why such a low percentage of people in the experimental group reported playing. Verifying this, when asked what they disliked about the game, qualitative feedback gained from the final term survey showed how subjects often raised issue with the complexity of the game, and lack of clear instructions, e.g.:

"I am used to playing games but couldn't make head nor tail of it and how to use it"

\section{"Instructions aren't easy to understand"}

Nevertheless, some positive feedback was received. Specifically, when subjects were asked what they liked about the game, some subjects ( 2 out of 10 residents who responded to this question) mentioned the suitability of the game for children, whilst others (6 out of 10 residents who responded to this question) mentioned they had found it easy to use and informative:

\section{"It is appealing to children"}




\section{"Easy to use and interesting game play. Very informative"}

Thus, the game was received in a positive manner by some subjects. However, on the whole, the SUS usability scale analyses and qualitative feedback highlight several issues in game play terms, including issues of poor game design, which can be built upon in future versions in order to increase likelihood of adherence and thus behaviour change potential. For example, this may include providing adaptive fonts as part of the game display (e.g. larger fonts for older people), and clearer, less wordy instructions on game play at the outset. We later reflect upon the limitations of the design process followed in the current research which appear to have led to reduced engagement in this instance.

\section{Discussion}

The current research explored the potential for a new serious game to motivate positive behaviour change in the context of energy demand reduction within the social housing sector. Using a 12-month longitudinal pilot study, changes in energy awareness and engagement in energy saving behaviours were assessed versus a no-game control. Overall, analysis revealed no evidence that the serious game was able to motivate behaviour change in this context; with no notable impact of gameplay found on engagement in the energy-saving behaviours over time. A similar pattern of results was found for energy awareness, with no overall impact of the intervention found over time. However, additional exploratory analyses focusing on individual items did reveal one finding of interest in terms of energy awareness. Specifically, subjects were found to be more likely to state that they did not understand how their homes used energy at the baseline versus final term stages. However, this effect was not found to be specific to the experimental-only condition, but in fact appeared to be part of a larger effect of increased energy understanding over time, across conditions. We later return to a discussion of the implications of this finding.

In terms of feedback on the EnergyCat game, feedback gathered from the experimental group at the final term stage highlighted several usability issues which resulted in relatively low levels of engagement. These included game complexity, difficulty in seeing the display features, and a lack of clear instructions at the outset in terms of gameplay objectives. Determining means of overcoming these issues and improving general usability should be prominent considerations in the development of future interventions in this context. For example, as mentioned previously, simply developing versions of the game which include adaptive fonts (e.g. larger fonts for older people), and clearer instructions at the outset may be instrumental in encouraging engagement in future. We note that the design process followed in the current research was limited in the sense that whilst feedback from social housing residents formed a crucial part of the initial idea scoping stage of the game design, residents were not involved in developing or testing final versions of the game prior to intervention launch. We recognise this as a key design flaw in the current research. It may be that if residents were asked to provide feedback on the game prior to launch, issues such as small font size and lack of clear instructions could have been addressed, potentially leading to substantial improvements in game usability. In line with previous research [49], we suggest that future researchers bear this in mind in the development of future serious games, and ensure that the target audience is involved in all stages of the design process, in order to maximise likelihood of effective engagement

In addition, many subjects found the game too time consuming; another key issue which could have been highlighted and addressed during the design process, had residents been involved in testing and approving later versions of the game. We suggest this may be particularly poignant issue when considering time poor social housing tenants, and that future researchers may also wish to focus on development of less time-intensive versions of the game, which enable the chooser to learn something about energy saving in a matter of minutes, in order to maximise likelihood of engagement from this population. A larger programme of research would also be needed in order to tease out the effects of different 
reward systems, and alternative main characters (e.g. other than the cat) on encouraging engagement from residents in this sector. We note that exploration of these issues was unfortunately beyond the scope of the current research, but these nevertheless remain interesting avenues for future exploration. What is more, we note that whilst the SUS scale was useful in providing some insight into issues surrounding game usage; more detailed feedback may have been gained using The Unified Theory of the Acceptance and Use of Technology (UTAUT2) [65]. Consequently, we suggest that this should be carefully incorporated into the assessment protocol for future interventions in order to gain more comprehensive insight into all of the factors which may have impacted upon consumer engagement.

However, some elements of the game design process were well implemented. Specifically, in line with suggestions made by Finjheer and van Oostendoorp [49] for designing an effective game for energy saving, we were keen to ensure that our serious game included rewards based on in-game personalisation opportunities, and this was effectively implemented in practice. In addition, on the basis of feedback gained from residents in early stages of game development, we hoped to develop and implement a fun and enjoyable game for energy saving, and the use of the 'EnergyCat' character as the central protagonist in the game was, to some extent, effective in achieving this. However, some residents perceived that this format may have been better suited to a younger demographic. Indeed, reflecting this, qualitative feedback gained from residents at the end of the trial period revealed that some subjects thought the game would be an effective educational tool for younger generations. As this feedback illustrates, there was a positive perception of the educational potential of the game amongst some subjects, suggesting that the implementation of our in-game missions and hints and tips were perceived by some to be effective in increasing understanding of domestic energy saving practices. We suggest that a future version of the game should be designed, bearing in mind, and taking into consideration, the needs and preferences of the older population sample as well, in order to achieve engagement across all age groups in this population subset.

As previously mentioned, our main analyses provided no evidence for any impact of the intervention on overall energy awareness. However, our additional exploratory analysis did reveal evidence for one finding of particular interest when looking at the individual energy awareness items over time, across conditions. Specifically, in line with predictions, subjects were found to be more likely to state they did not understand how their homes used energy at the baseline vs. final term stages. The lack of any interaction effect means this finding cannot be attributed to the experimental manipulation, but rather appears to represent a uniform increase in understanding across conditions, over time. We suggest this may be attributable to completion of the surveys themselves. Specifically, the surveys indirectly provided subjects in both conditions with information on energy saving, via the list of energy-saving behaviours subjects were asked to consider. In previous research, we found that subjects reported they would be interested in receiving hints and tips to save money on their energy bills [43]. Whilst the EnergyCat game was designed with this feedback in mind, the fact that increased awareness was found across conditions shows this cannot be accounted for by the energy saving tips provided within the game itself. Rather it appears that provision of the surveys may have provided a means of achieving this, through indirect supplementation of information on energy-saving behaviours. This suggestion is supported by a series of qualitative one-on-one interview sessions that were conducted with residents in the twomonth period following the end of the intervention [66]. In these interview sessions, some residents were found to report increased awareness due to the information provided within the surveys themselves (see [66]). Thus, we find evidence that future behaviour change interventions containing a simple physical list of hints and tips on energy saving may prove effective in increasing energy awareness and understanding in the social housing sector. However, it is important to note that this effect was only found to be prevalent for one out of nine individual items in the additional exploratory analyses. As such, interpretation of this result must be treated with caution. Further, although evidence was found for an increase in 
energy understanding on this particular individual measure, this was not found to translate into behaviour change. Our analyses into psychological barriers to behaviour change at the final term stage provides insight as to why this may be the case.

Specifically, at the final term stage we explored psychological barriers to behaviour change in order to gain insight into determinants of energy behaviour within the social housing sector. Analyses revealed generally high levels of interest in energy saving. It appears that the lack of translation of the effects on energy awareness into action (in terms of engagement in energy saving behaviours over time) was not attributable to a lack of interest. In fact, analyses revealed three key reasons as potential explanations. These centred on: low baseline levels of energy usage in this sector, health reasons, and the perception that further reductions to energy usage would jeopardise hedonic values, in terms of the experience of comfort. Consequently, although the current trial did not find any prominent effects of serious gaming on energy behaviour change, we suggest that this may be attributable to usability issues associated with this particular version of the game, and pitfalls of the design process utilised, rather than a failure of gamification in the social housing sector. The results of this section of analyses provide useful insight as to decision-making processes utilised by householders within the social housing sector; and provides evidence for generally high interest in energy saving for this population, substantiating the need for further research which may help householders to achieve this. A further limitation of the current research was a lack of effective communication about means by which subjects could achieve energy reductions without jeopardising hedonic values, in terms of the experience of comfort. Indeed, agreement with this statement was found to be significantly higher than all other potential explanations, suggesting this played a key role for the majority of social housing tenants when it came to making decisions that would directly affect their consumption levels. Going forward we suggest that future behaviour change interventions focused on social housing should endeavour make this information prominent at the outset, as well as addressing the usability issues previously outlined. Crucially, this should also involve a design process which involves greater involvement from residents throughout the game development period. Based on lessons learned from the trial presented here, we believe that if each of these issues is carefully addressed in future versions of the game, then substantial potential remains for gamification as a tool to encourage energy conservation in the UK social housing sector.

\subsection{Conclusions and implications}

The government's fuel poverty strategy aims to increase the energy efficiency of vulnerable households [67]. Given the effectiveness of serious games as a behaviour change tool for reducing domestic energy demand in wider populations [e.g. 39-42, 44-45], the current research was designed to explore the potential for our new serious game, 'EnergyCat', to increase the energy efficiency of social housing residents in the UK. Given most previous research has focused on shorter term effects of serious gaming in energy behaviour change [39-42], our main aims were twofold: 1) to explore the longevity of behaviour change effects of serious gaming in energy reduction, and 2) to explore whether behavioural effects of serious gaming extend to vulnerable populations, such as social housing.

The pilot study presented here has important implications in terms of informing serious game design in the context of domestic energy saving. Specifically, our results illustrated that the game had limited impact in inciting behaviour change in this context, with no notable differences found across the experimental versus control conditions at the final term stage, or over time. To understand why the game did not have the intended impact, it is important to not only consider the characteristics of the game but also the context around the game design process. Previous research on the same target population revealed that, from the outset (prior to getting access to the game), residents held generally negative attitudes towards the prospect of using a serious game about energy use and saving (for more detail see [43]). In particular, elderly and disabled residents lacked confidence in using internet and computers, and found it difficult to imagine how a serious energy game could benefit them. With this context in 
mind, workshops were set up with the game developer aimed at gathering feedback and information from the residents throughout the game design process. However, these workshops were only attended by a small number of residents, and overall interest in these workshops was low. Therefore, the game design process was not a true 'co-design' process, as intended. This may have contributed to some of the issues with the game design (in terms of complexity and usability), and meant that the game did not fit the needs of the users as well as it could have done. This in turn may have limited the impact of the game in inciting behaviour change. The initial negative perception toward serious energy games, along with a lack of participation in co-designing activities is likely to be a challenge for any future attempts at designing serious games to encourage energy saving behaviours in the social housing context. Overcoming this challenge will be key to ensure that a future game fits the abilities and needs of the users better. Once a co-design process is in place, the current research has highlighted two aspects of particular interest for further research. Firstly, qualitative feedback revealed that the social housing population subset were relatively time poor, lacked confidence in using computers and the internet, and had little interest in gaming in general. The latter fits with the low levels of IT literacy often found in the social housing sector [47]. We therefore suggest that future behaviour change interventions designed to increase the energy efficiency of fuel poor households may look to develop less time intensive versions of the game that are easier to use. Specifically, focussing on designing a game with users in mind that are likely to have low IT literacy and may be elderly and/or disabled. Here one could draw on previous research which has started to identify the characteristics serious games should have to engage elderly populations, such as the use of adaptive fonts (cf. [68]). It may also be helpful to develop simple non-digitalised solutions alongside a serious game in order to maximise interest from residents in this social housing population. Secondly, our exploration of psychological barriers to behaviour change demonstrated that several barriers exist which continue to prevent social housing tenants from consuming less energy. These were focused around low baseline levels of energy usage in this sector, health reasons, and the fact that residents perceived further reductions to their energy usage may jeopardise their comfort levels at home. Future behaviour change interventions must subsequently look to determine means of overcoming these barriers in order to ensure future schemes have the greatest chance of success, and we have discussed potential strategies for achieving this. In sum, more research is needed in order to establish whether serious gaming can lead to lasting reductions in energy demand across society in general. However, our results illustrate that the approach, as used here, certainly appears to have limited potential within the social housing sector. However, potential remains for behaviour change if improved, less time intensive versions of the game are developed in future, in close collaboration with users at all stages of the design process. 


\section{References}

[1] Committee on Climate Change, 2017 Report to Parliament - Meeting Carbon Budgets: Closing the Policy Gap, 2017. Accessed on: Jun. 10, 2019. [Online]. Available: https://www.theccc.org.uk/publication/2017-report-to-parliament-meeting-carbon-budgetsclosing-the-policy-gap/

[2] G. P. Peters, R. M. Andrew, T. Boden, J. G. Canadell, P. Ciais, C. Le Quéré, G. Marland, M. R. Raupach and C. Wilson, "The Challenge to Keep Global Warming Below $2{ }^{\circ} \mathrm{C}$ " Nature Climate Change, vol. 3, pp. 4 - 6, 2013. doi: https://doi.org/10.1038/nclimate1783

[3] J. McGonigal, Why Games Make Us Better and How They Can Change the World. London: Penguin, 2011.

[4] S. P. Waltz and S. Deterding, "An Introduction to The Gameful World" in The Gameful World: Approaches, Issues, Applications, S. P. Waltz, and S. Deterding, Eds., Cambridge, Massachusetts: The MIT Press, 2015, pp. 1 - 14.

[5] American Council for an Energy-Efficient Economy. Gamified Energy Efficiency Programs: Research Report B1501. Accessed on: Jan. 2, 2020. [Online]. Available: http://aceee.org/research-report/b1501

[6] M. Bang, C. Torstensson and C. Katzeff, "The PowerHhouse: A Persuasive Computer Game Designed to Raise Awareness of Domestic Energy Consumption". In Persuasive Technology. PERSUASIVE 2006. Lecture Notes in Computer Science, W. A. IJsselsteijn, Y. A. W. de Kort, C. Midden, B. Eggen, and E. van den Hoven, Eds., Springer: Berlin, 2006, vol. 3962, pp. 123 132.

[7] D. Kotsopoulos, C. Bardaki, T. G. Papaioannou, S. Lounis and K. Pramatari, "Agile UserCentered Design of an IoT-Enabled Gamified Intervention for Energy Conservation", IADIS International Journal on WWW/Internet, vol. 16(1), pp. 1 - 25, 2018. Accessed on: Jan. 6, 2020. [Online]. Available: http://www.iadisportal.org/ijwi/papers/2018161101.pdf

[8] Department for Business, Energy and Industrial Strategy, Energy Consumption in the UK: July 2017. Accessed on: Jun. 31, 2019. [Online]. Available: https://assets.publishing.service.gov.uk/government/uploads/system/uploads/attachment_data /file/633503/ECUK_2017.pdf

[9] G. T. Gardner and P. C. Stern, Environmental Problems and Human Behavior. Boston: Pearson, 2002.

[10] K. Hobson, "Thinking Habits into Action: The Role of Knowledge and Process in Questioning Household Consumption Practices", Local Environment, vol. 8, no. 1, pp. 95 - 112, 2003. doi: https://doi.org/10.1080/135498303200041359

[11] American Psychological Association (APA), Psychology and Global Climate Change: Addressing a Multifaceted Phenomenon and Set of Challenges, 2009. Accessed on: May. 10, 2019. [Online]. Available: http://www.apa.org/science/about/publications/climate-changebooklet.pdf

[12] C. Fischer, "Feedback on Household Electricity Consumption", Energy Efficiency, vol. 1, no. 1 , pp. 79 - 104, 2008. doi: https://doi.org/10.1007/s12053-008-9009-7

[13] J. Burgess and M. Nye, "Re-materialising Energy Use through Transparent Monitoring Systems", Energy Policy, vol. 36, pp. $4454-4459$, 2008. doi: https://doi.org/10.1016/j.enpol.2008.09.039

[14] H. Allcott and N. Wozny, "Gasoline Prices, Fuel Economy, and the Energy Paradox", NBER Working Paper No. 18583, 2012. doi: https://doi.org/10.3386/w18583

[15] S. Frederick, G. Loewenstein and T. O' Donoghue, "Time Discounting and Time Preference: A Critical Review", Journal of Economic Literature, vol. 40, pp. 350 - 401, 2002. doi: https://doi.org/10.1257/jel.40.2.351

[16] W. Abrahamse, L. Steg, C. Vlek and T. Rothengatter, "The Effect of Tailored Information, Goal Setting, and Tailored Feedback on Household Energy Use, Energy-related Behaviours, and Behavioural Antecedents", Journal of Environmental Psychology, vol. 27, pp. 265 - 276, 2007. doi: https://doi.org/10.1016/j.jenvp.2007.08.002

[17] A. Faruqui, S. Sergici and A. Sharif, "The Impact of Informational Feedback on Energy Consumption - A Survey of the Experimental Evidence", Energy, vol. 35, pp. 1598 - 1608 2010. doi: https://doi.org/10.1016/j.energy.2009.07.042

[18] P. W. Schultz, M. Estrada, J. Schmitt, R. Sokoloski and N. Silva-Send, "Using In-Home Displays to Provide Smart Meter Feedback about Household Electricity Consumption: A Randomized Control Trial comparing Kilowatts, Cost, and Social Norms" Energy, vol. 90, pp. 351 - 358, 2015. doi: https://doi.org/10.1016/j.energy.2015.06.130

[19] S. Darby, The Effectiveness of Feedback on Energy Consumption: A Review for Defra of the Literature on Metering, Billing and Direct Displays, 2006. Accessed on: Jan. 6, 2020. [Online]. Available: https://www.eci.ox.ac.uk/research/energy/downloads/smart-metering-report.pdf 
[20] D. Kotsopoulos, C. Bardaki, S. Lounis and K. Pramatari, "Employee Profiles and Preferences towards loT-enabled Gamification for Energy Conservation", International Journal of Serious Games, vol. 5, no. 2, pp. 65 - 85, 2018. doi: https://doi.org/10.17083/ijsg.v5i2.225

[21] H. Wilhite and R. Ling, "Measured Energy Savings from a More Informative Energy Bill", Energy and Buildings, vol. 22, pp. 145 - 155, 1995. doi: https://doi.org/10.1016/0378-7788(94)00912-4

[22] K. Buchanan, R. Russo and B. Anderson, "The Question of Energy Reduction: The Problem(s) with Feedback", Energy Policy, vol. 77, pp. 89 - 96, 2015. doi: https://doi.org/10.1016/j.enpol.2014.12.008

[23] T. Schwartz, G. Stevens, T. Jakobi, S. Denef, L. Ramirez, V. Wulf and D. Randall, "What People Do with Consumption Feedback: A Long-Term Living Lab Study of a Home Energy Management System", Interacting with Computers, 2014. doi: https://doi.org/10.1093/iwc/iwu009

[24] J. Goodhew, S. Pahl, T. Auburn and S. Goodhew, "Making Heat Visible: Promoting Energy Conservation Behaviours through Thermal Imaging", Environment \& Behavior, vol. 47, pp. 1059 - 1088, 2015. doi: https://doi.org/10.1177/0013916514546218

[25] C. Boomsma, J. Goodhew, S. Goodhew and S. Pahl, "Improving the Visibility of Energy Use in Home Heating in England: Thermal Images and the Role of Visual Tailoring", Energy Research \& Social Science, vol. 14, pp. 111 - 121, 2016. doi: https://doi.org/10.1016/j.erss.2016.01.005

[26] S. Pahl, J. Goodhew, C. Boomsma and S. R. J. Sheppard, "The Role of Energy Visualization in Addressing Energy Use: Insights from the eViz Project”, Frontiers in Psycholology, vol. 7, pp. 92, 2016. doi: https://doi.org/10.3389/fpsyg.2016.00092

[27] A. Lucero, E. Karapanos, J. Arrasvuori and H. Korhonen, "Playful or Gameful? Creating Delightful User Experiences" Interactions, vol. 21, no. 3, pp. 34 - 39, 2014. doi: https://doi.org/10.1145/2590973

[28] A. Bandura, Social Learning Theory, 1971. Accessed on: Jun. 30, 2019. [Online]. Available: http://www.asecib.ase.ro/mps/Bandura_SocialLearningTheory.pdf

[29] C. Abt, Serious Games. New York: The Viking Press, 1970.

[30] D. Dicheva, C. Dichev, G. Agre and G. Angelova, "Gamification in Education: A Systematic Mapping Study", Journal of Educational Technology \& Society, vol. 18, no. 3, pp. 75 - 88, 2015. Stable URL: https://www.jstor.org/stable/jeductechsoci.18.3.75

[31] U. Ritterfeld, M. Cody and P. Vorderer, Serious Games: Mechanisms and Effects. Routledge: New York, USA, 2010.

[32] W. Abrahamse, L. Steg, C. Vlek and T. Rothengatter, "A Review of Intervention Studies aimed at Household Energy Conservation", Journal of Environmental Psychology, vol. 25, no. 3, pp. 273 - 291, 2005. doi: https://doi.org/10.1016/j.jenvp.2005.08.002

[33] W. Abrahamse and L. Steg, "Social Influence Approaches to Encourage Resource Conservation: A Meta-analysis", Global Environmental Change, vol. 23, no. 6, pp. $1773-1785$, 2013. doi: https://doi.org/10.1016/j.gloenvcha.2013.07.029

[34] J. W. Bolderdijk, L. Steg, E. S. Geller, P. K. Lehman and T. Postmes, "Comparing the Effectiveness of Monetary versus Moral motives in Environmental Campaigning", Nature Climate Change, vol. 3, pp. 413 - 416, 2012. doi: https://doi.org/10.1038/nclimate1767

[35] B. F. Skinner, "The Experimental Analysis of Behaviour", American Scientist, vol. 45(4), pp. 343 - 371, 1957. doi: https://doi.org/10.1109/JRPROC.1957.278375

[36] V. Griskevicius, J. Tybur and B. Van den Bergh, "Going Green to be Seen: Status, Reputation, and Conspicuous Conservation", Journal of Personality and Social Psychology, vol. 98, no. 3, pp. 392 - 404, 2010. doi: https://doi.org/10.1037/a0017346

[37] E. A. Locke and G. P. Latham, "Building a Practically Useful Theory of Goal Setting and Task Motivation", American Psychologist, vol. 57, no. 9, pp. 705 - 717, 2002 . doi: https://doi.org/10.1037/0003-066X.57.9.705

[38] D. McKenzie-Mohr and W. Smith, Fostering Sustainable Behaviour: An Introduction to Community-Based Social Marketing. Gabriola Island, British Columbia, Canada: New Society Publishers, 1999.

[39] M. Ro, M., Brauer, K. Kuntz, R. Shukla and I. Bensch, "Making Cool Choices for Sustainability: Testing the Effectiveness of a Game-based Approach to Promoting Pro-environmental Behaviours", Journal of Environmental Psychology, vol. 53, pp. 20 - 30, 2017. doi: https://doi.org/10.1016/j.jenvp.2017.06.007

[40] B. Reeves, J. Cummings, J. Scarborough and L. Yeykelis, "Increasing Energy Efficiency with Entertainment Media: An Experimental and Field Test of the Influence of a Social Game on Performance of Energy Behaviors", Environment and Behavior, vol. 47, no. 1, pp. $102-115$, 2015. doi: https://doi.org/10.1177/0013916513506442

[41] B. Cowley and C. Bateman, "Green My Place: Evaluation of a Serious Social Online Game Designed to Promote Energy Efficient Behaviour Change", International Journal of Serious Games, vol. 4, no. 4, pp. 71 - 90, 2017. doi: https://doi.org/10.17083/ijsg.v4i4.152

[42] B. Orland, N. Ram, D. Lang, K. Houser, N. Kling and M. Coccia, "Saving Energy in an Office Environment: A Serious Game Intervention”, Energy and Buildings, vol. 74, pp. 43 - 52, 2014. doi: https://doi.org/10.1016/j.enbuild.2014.01.036 
[43] C. Boomsma, R. J. Hafner, S. Pahl, R. V. Jones and A. Fuertes, "Should We Play Games where Energy is Concerned? Perceptions of Serious Gaming as a Technology to Motivate Energy Behaviour Change among Social Housing Tenants", Sustainability: Special Issue Social Innovations in the Energy Transition, vol. 10, no. 6, 2018. doi: https://doi.org/10.3390/su10061729

[44] D. Johnson, E. Horton, R. Mulcahy and M. Foth, "Gamification and Serious Games within the Domain of Domestic Energy Consumption", Renewable and Sustainable Energy Reviews, vol. 73, pp. 249 - 264, 2017. doi: https://doi.org/10.1016/j.rser.2017.01.134

[45] American Council for an Energy-Efficient Economy, Gamified Energy Efficiency Programs: Research Report B1501, 2015. Accessed on: Jul. 2, 2019. [Online]. Available: http://aceee.org/research-report/b1501

[46] A. Pittini, G. Koessl, J. Dijol, E. Lakatos and L. Ghekière, The State of Housing in the EU 2017, 2017. Accessed on: Jun. 25, 2019. [Online]. Available: http://www.housingeurope.eu/file/614/download

[47] J. Hills, Ends and Means: The Future Roles of Social Housing in England, CASEreport 34 ISSN 1465-3001. London: ESRC Research Centre for the Analysis of Social Exclusion, 2007.

[48] A. Druckman and T. Jackson, "Household Energy Consumption in the UK: A Highly Geographically and Socio-economically Disaggregated Model", Energy Policy, vol. 36, no. 8, pp. 3177 - 3192, 2008. doi: https://doi.org/10.1016/j.enpol.2008.03.021

[49] J. D. Fijnheer and H. van Oostendorp, "Steps to Design a Household Energy Game", International Journal of Serious Games, vol. 3, no. 3, 2016. doi: https://doi.org/10.17083/ijsg.v3i3.131

[50] FremenCorp, UOP and ISEP, EnerGAware: Game Design and Software Specifications and Architecture (Public Summary), 2016. Accessed on: May. 9, 2020. [Online]. Available: http://energaware.eu/downloads/EnerGAware_D3.1_Game\%20Design\%20And\%20Software \%20Specifications\%20And\%20Architecture\%20public_r1.pdf

[51] FremenCorp, UOP, ISEP and UPC, EnerGAware: Serious Game Beta Version, 2017. Accessed on: May. $2020 . \quad$ [Online]. http://energaware.eu/downloads/EnerGAware_D3.5_Serious_Game_Beta_\%20Version_r1.pd $f$

[52] Z. Yu, B. C. M. Fung, F. Haghighat, H. Yoshino and E. Morofsky, "A Systematic Procedure to Study the Influence of Occupant Behavior on Building Energy Consumption", Energy and Buildings, vol. 43, pp. 1409 - 1417, 2011. doi: https://doi.org/10.1016/j.enbuild.2011.02.002

[53] M. R. Porto, D. Hildebrandt, M. Arias, A. Fuentes, M. Pérez, K. O’Malley, R. Knights and J. Brookes, 3-E Houses: Saving Energy and the Environment Across Europe - Final Report, 2013. Accessed on: Jan. 7, 2020. [Online]. Available: https://cordis.europa.eu/docs/projects/cnect/1/250491/080/reports/002ARES3404476FinalReportfinalversion.pdf

[54] W. B. Korte, G. Vogt and K. Gareis "eSESH - Saving Energy in Social Housing with ICT", 2013. doi: 10.13140/RG.2.2.12418.27849

[55] G. Vogt, E. Dashja and W. B. Korte, BECA: Balanced European Conservation Approach ICT Services for Resource Saving in Social Housing - Final Report, 2015. Accessed on: Jan. 7 $2020 . \quad$ [Online]. Available:
project.eu/fileadmin/beca/documents/beca_final_report_final.pdf

[56] Department for Communities and Local Government, English Housing Survey Social Rented Sector: A Report on the Characteristics and Circumstances of Social Renters in England, 2017. Accessed on: Jul. 2, 2019. [Online]. Available: https://www.gov.uk/government/statistics/english-housing-survey-2015-to-2016-socialrentedsector

[57] J. Thøgersen and A. Grønhøj, "Electricity Saving in Households - A Social Cognitive Approach", Energy Policy, vol. 38, pp. 7732 - 7743, 2010. doi: https://doi.org/10.1016/j.enpol.2010.08.025

[58] K. A. Parkhill, C. Demski, C., Butler, A. Spence and N. Pidgeon, Transforming the UK Energy System: Public Values, Attitudes and Acceptability - Synthesis Report, 2013. Accessed on: Jan. 14, 2020. [Online]. Available: http://www.ukerc.ac.uk/publications/transforming-the-uk-energysystem-public-values-attitudes-and-acceptability.htm

[59] E. Matthies, I. Kastner, A. Klesse and H. J. Wagner, "High Reduction Potentials for Energy User Behaviour in Public Buildings: How Much can Psychology-based Interventions Achieve?", Journal of Environmental Studies and Sciences, vol. 1, no. 3, pp. 241 - 255, 2011. doi: https://doi.org/10.1007/s13412-011-0024-1

[60] B. Gatersleben, L. Steg and C. Vlek, "Measurement and Determinants of Environmentally Significant Consumer Behavior", Environment and Behavior, vol. 34, no. 3, pp. 335 - 362, 2002. doi: https://doi.org/10.1177/0013916502034003004

[61] F. Ölander and J. Thøgersen, "Informing versus Nudging in Environmental Policy", Journal of Consumer Policy, vol. 37, pp. 341 - 356, 2014. doi: https://doi.org/10.1007/s10603-014-9256-2

[62] E. R. Frederiks, K. Stenner and E. V. Hobman, "Household Energy Use: Applying Behavioural Economics to Understand Consumer Decision-Making and Behaviour", Renewable and 
Sustainable Energy Reviews, vol. 41, pp. 1385 - 1394, 2015. doi: https://doi.org/10.1016/j.rser.2014.09.026

[63] A. Field, Discovering Statistics Using IBM SPSS Statistics (5th Edition). London: Sage Publications Ltd, 2017.

[64] J. Brooke, "SUS - A Quick and Dirty Usability Scale" in Usability Evaluation in Industry, P. W. Jordan, B. Thomas, B. A. Weerdmeester and I. L. McClelland, Eds., London: Taylor \& Francis, 1996, pp. $189-194$.

[65] V. Venkatesh, J. Y. L. Thong and X. Xu, "Consumer Acceptance and Use of Information Technology: Extending the Unified Theory of Acceptance and Use of Technology", MIS Quarterly, vol. 36, no. 1, pp. 157 - 178, 2012. doi: https://doi.org/10.2307/41410412

[66] R. J. Hafner, S. Pahl, R. V. Jones and A. Fuertes, "Energy Use in Social Housing Residents in the UK and Recommendations for Developing Energy Behaviour Change Interventions", Journal of Cleaner Production, vol. 251, pp. 119643, 2020. doi: https://doi.org/10.1016/j.jclepro.2019.119643

[67] Department of Energy and Climate Change, Cutting the Cost of Keeping Warm: A Fuel Poverty Strategy for England, 2015. Accessed on: Jun. 20, 2019. [Online]. Available: www.gov.uk/government/publications/cutting-the-cost-of-keeping-warm

[68] P. H. Robert, A. König, H. Amieva, S. Andrieu, F. Bremond, R. Bullock, M. Ceccaldi, B. Dubois, S. Gauthier, P-A. Kenigsberg, S. Nave, J. M. Orgogozo, J. Piano, M. Benoit, J. Touchon, B. Vellas, J. Yesavage and V. Manera, "Recommendations for the Use of Serious Games in People with Alzheimer's Disease, Related Disorders and Frailty", Frontiers in Aging Neuroscience, vol. 6, article 54, 2014. doi: https://doi.org/10.3389/fnagi.2014.00054

\section{Acknowledgements}

Funding: This research was funded by Horizon 2020 Framework Programme 649673. We also acknowledge and thank Fremen Corp for their role in the game design process. 